\title{
Erratum to: Contributions of Disease Severity, Psychosocial Factors, and Cognition to Behavioral Functioning in US Youth Perinatally Exposed to HIV
}

\author{
Katrina D. Hermetet-Lindsay ${ }^{1,6,7}$ - Katharine F. Correia ${ }^{2}$ Paige L. Williams ${ }^{2}$ • \\ Renee Smith $^{3}$ - Kathleen M. Malee ${ }^{4} \cdot$ Claude A. Mellins $^{5} \cdot$ Richard M. Rutstein $^{1}$. \\ for the Pediatric HIV/AIDS Cohort Study
}

Published online: 27 August 2016

(c) Springer Science+Business Media New York 2016

\section{Erratum to: AIDS Behav \\ DOI 10.1007/s10461-016-1508-5}

In the original publication of the article, the first and last names of most of the authors were not displayed correctly. All author names are correctly displayed with this erratum.

The corrections were updated in the original publication as well.

The online version of the original article can be found under doi:10.1007/s10461-016-1508-5.

Katrina D. Hermetet-Lindsay

klindsay@chmca.org

1 Division of General Pediatrics, Children's Hospital of Philadelphia, Philadelphia, PA, USA

2 Department of Biostatistics, Harvard. T. H. Chan School of Public Health, Boston, MA, USA

3 Department of Pediatrics, University of Illinois at Chicago Children's Hospital, Chicago, IL, USA

4 Department of Psychiatry and Behavioral Sciences, Northwestern University Feinberg School of Medicine, Chicago, IL, USA

5 Department of Psychiatry, HIV Center for Clinical and Behavioral Studies, Columbia University and New York State Psychiatric Institute, New York, USA

6 Lehigh University School Psychology Program, Bethlehem, PA, USA

7 Division of Neurobehavioral Health, Akron Children's Hospital, 215 W. Bowery St. Suite 4500, Akron, OH 44308-1062, USA 